\title{
Systematic mapping of studies published in Indian Journal of Pharmacy Practice from 2008-2015
}

\author{
Pramil Tiwari, Ruchi Singhal, Rajiv Ahlawat \\ Department of Pharmacy Practice, National Institute of Pharmaceutical Education and Research (NIPER), Sector 67, S.A.S. Nagar, \\ Punjab-160062, INDIA.
}

\begin{abstract}
Introduction: Pharmacy practice profession had evolved in India over a period of time, but still a lot of work needs to be done. Indian journal of pharmacy practice was started in 2008 to meet the demand of a required forum for the professionals working in the area of pharmacy practice. Objective: To map the publications of Indian Journal of Pharmacy Practice (IJOPP) for a period of Oct 2008 to Jun 2015. Method: This study was carried out for a period of four months from Sept 2015 to Dec 2015. The papers published in IJOPP, both hard and electronic versions from Oct 2008 to Jun 2015 were screened. Publications were classified with respect to publication year, nature of the publication, therapeutic area, area of research, study design, data source, study duration, authors' details, geographical region where the study was conducted, affiliated college and hospitals, nature of healthcare setting, and set of subjects/patients in the study. All the results were represented as percentage(s) and number(s). Results: A total of 321 publications have been published till date. The number of research articles were 203 in number followed by review, case report, short communication and letter to editor (68, 34, 15 and 1, respectively). Infectious diseases were found to be the most common therapeutic area in research and review categories ( 8 and 43, respectively). Maximum numbers of publications were in pharmacovigilance (57). 93 (of 169) publications explicitly reported the study design and 28 were cross-sectional (28/38 publications did not report study design). Out-patients data were used in 57 publications (out of 193, publications reported data collection source). Study duration was 6 months in 90 (out of total 164, publications). Four authors were involved in 83 publications (out of total 321). Corresponding authors in 278 (278/313) publications were from pharmacy background. 161(161/276) publications belonged to pharmacy practice department. Maximum number of publications were from Karnataka (90/321). Study sites were hospitals in 171 publications. 146 studies were carried out in tertiary care hospital. Out of total, 72 publications included the adults and geriatrics as study population. Conclusion: Infectious diseases and pharmacovigilance were found to be most studied area. Study designs were not reported in 38 publications. Most of the studies were carried out for less than or equal to 6 months. Adults and geriatric "patients/subjects" groups were found to be most commonly studied.
\end{abstract}

Key words: Indian Journal of Pharmacy Practice, IJOPP, Pharmacy Practice, Hospital Pharmacy, Clinical Pharmacy, India.

\section{INTRODUCTION}

Pharmacy education traditionally is product oriented since its inception at Banaras Hindu University in 1937. ${ }^{1}$ Due to decreasing opportunities in industry oriented jobs, and to keep pace with the global practices, the pharmacy education shifted towards the pharmaceutical care with inception of pharmacy practice course in 1997 at one of the colleges in southern India. ${ }^{2}$

Pharmacy practice had evolved in India over a period of time despite the fact that, regulatory framework of India does not recognize the clinical pharmacist's need at national level., ${ }^{3,4}$ First degree in pharmacy practice was started in the year 1997 at JSS, Mysuru followed by

DOI: 10.5530/ijopp.9.2.10

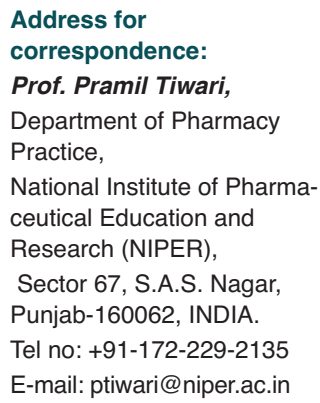


NIPER, Mohali (2002) and Manipal.5,6 As per available references, presently 48 colleges in India are offering M. Pharm in pharmacy practice. ${ }^{7}$ According to Pharmacy Council of India, a total of 201 colleges in India are offering Pharm.D and Pharm.D (Post Baccalaureate). Most of them are situated in Andhra Pradesh followed by Karnataka, Kerala, Tamil Naidu, Maharashtra and others. ${ }^{8}$

The research activity by the researchers of pharmacy practice did not fit into the journals dealing with pharmaceutical sciences and drug discovery. Therefore, to cater this increasing demand of publication of such research activities, Indian Journal of Pharmacy Practice (IJOPP) was started in Oct 2008.

IJOPP publishes research and review work in various areas of pharmacy practice including hospital pharmacy, community pharmacy, clinical pharmacy, pharmacovigilance, pharmaceutical care, pharmacoeconomics, clinical research, clinical pharmacokinetics and other related areas. ${ }^{9} \mathrm{IJOPP}$ is the official quarterly peer-reviewed journal of Association of Pharmaceutical Teachers of India (APTI). Till date, lot of research work was published from different institutes in different therapeutic categories all across India.

Efforts was made to map the publications in IJOPP for a period of Oct 2008 to Jun 2015. The publications were classified with respect to publication year, nature of the publication, therapeutic area, area of research, study design, data source, study duration, authors details, geographical region where the study was conducted, affiliated college and hospitals, nature of healthcare setting, and set of subjects/patients in the study.

The findings from this study will help in understanding and creating the evidence on the trend of ongoing research in area of pharmacy practice.

\section{Method}

This study was carried out for a period of four months between Sept 2015 to Dec 2015 to map the nature of publications of IJOPP from Oct 2008 to June 2015. Two independent investigators, and co-authors of this manuscript, reviewed the data so extracted. The random verification of the tabulated data was performed by the third author. As detailed below disagreements on any pertaining issue were resolved by consensus between all the authors.

\section{Data source and search strategy}

Electronic format and hard copies of published issues of IJOPP from Oct 2008 to June 2015 were used for the data extraction. ${ }^{?}$

\section{Data extraction}

Information extracted from publication with respect to publication year, nature of the publication, therapeutic area, area of research, study design, data source, study duration, authors details, geographical region where the study was conducted, affiliated college and hospitals, nature of healthcare setting, and set of subjects/patients in the study.

\section{Data analysis}

Nature of publication: The studies were classified into original research article, review article, short communication, case report, and letter to editor. ${ }^{9}$

Therapeutic area: Therapeutic areas covered under the studies were classified into infectious diseases (Antimicrobials use and associated side effects, malaria, vaginitis, skin infections, swine flu, tuberculosis, HIV/AIDS, wound infections, and surgical site infections), Cardiovascular disease (hypertension, anemia, arrhythmia, coagulation), chronic kidney disease, Gastro-intestinal tract disorders (cirrhosis, hepatitis, jaundice, diarrhea), ophthalmic disorders, gynaecological disorders, carcinomas, skin disorders, metabolic disorders(obesity, thyroid disorders, T2DM), psychiatric problems, pulmonological disorders and others (pain, addiction, chronic diseases, rheumatoid arthritis and poisoning). ${ }^{10}$

Area of research: Drug utilization (DUR), drug related problems (DRP), adverse drug reaction (ADR) reporting, medication adherence, prevalence, survey, Quality of life, treatment effectiveness, costing, and validation. ${ }^{11,12}$

Study designs: Prospective, retrospective, cross-sectional, Combined Prospective and Retrospective cohort (Bidirectional), descriptive studies, and clinical trials (interventional studies). ${ }^{13-15}$

Data source: The source of data in the publications was classified into in-patients records, out-patient data, Medical record department (MRD), database, community, doctors and miscellaneous (pharmacist, combination of any category mentioned above). ${ }^{12}$

Study durations: The studies were classified into four categories ( $\leq 6$ months, $>$ 6months $-<1$ year, 1 Year, $>1$ year).

Authors: Information on number of authors was evaluated and affiliation of authors was also analyzed. Data on departments were categorized into pharmacy practice, clinical research, other department of pharmacy (pharmacology, pharmacognosy, pharmaceutical chemistry, pharmaceutical sciences and pharmaceutical MBA), and Miscellaneous (biotechnology, medicine, social and administrative sciences, health sciences, and health human services). Data with respect to area of working of corresponding author was evaluated in terms of pharmacy background, medicine, and others.

Indian Journal of Pharmacy Practice, Vol 9, Issue 2, Apr-Jun, 2016 
Table 1: Profile of publications year-wise $(\mathrm{N}=321)$

\begin{tabular}{cccccccccc}
\hline Issues & $\mathbf{2 0 0 8}$ & $\mathbf{2 0 0 9}$ & $\mathbf{2 0 1 0}$ & $\mathbf{2 0 1 1}$ & $\mathbf{2 0 1 2}$ & $\mathbf{2 0 1 3}$ & $\mathbf{2 0 1 4}$ & $\mathbf{2 0 1 5}$ & Grand Total \\
\hline Apr-Jun & $\mathrm{X}$ & 13 & 9 & 12 & 13 & 15 & 7 & 7 & 76 \\
Jan-Mar & $\mathrm{X}$ & 12 & 9 & 12 & 12 & 14 & 12 & 8 & 79 \\
Jul-Sep & $\mathrm{X}$ & 12 & 10 & 14 & 16 & 15 & 12 & $\mathrm{X}$ & 79 \\
Oct-Dec & 11 & 12 & 11 & 12 & 15 & 16 & 10 & $\mathrm{X}$ & 87 \\
Grand Total & $\mathbf{1 1}$ & $\mathbf{4 9}$ & $\mathbf{3 9}$ & $\mathbf{5 0}$ & $\mathbf{5 6}$ & $\mathbf{6 0}$ & $\mathbf{4 1}$ & $\mathbf{1 5}$ & $\mathbf{3 2 1}$ \\
\hline
\end{tabular}

Study regions: Categorization of regions of different studies was done state-wise for the India. The international studies formed a separate group.

Nature of healthcare setting: The study sites were classified into pharmacy setting, colleges/universities, community, and hospitals. Hospitals were further classified into primary care, secondary care, tertiary care, teaching hospitals, private and government hospitals(16). Study sites were further classified into in-house and off-campus.

Set of subjects/patients in the study: Studies were analyzed according to different age groups including adults, geriatrics, pediatrics, all of them, and any of two population.

\section{Statistical analysis}

Microsoft-excel 2010 was used for data organization and analysis. Results were represented as proportion and number in the form of table and figures.

\section{RESULTS}

Indian Journal of Pharmacy Practice (IJOPP) was started in 2008; and, appears every quarter. Its first issue contained research work of Oct-Dec 2008. It has come out with total of 321 publications till June 2015 (Table 1).

IJOPP published 60 publications in 2013 which is highest number till date followed by 56 publications in 2012 (Figure 1).

Publications were categorized into following five headings i.e. Research article, review article, case report, short communication (Research (7) and Review (8)) and letter to editor. Amongst publications, research articles were 203 out of 321 and review articles were 68 out of 321 (Figure 2).

Among total 76 review publications (68 review articles and 8 short communications review), 31 studies focused on a therapeutic area. The majority of therapeutic areas covered by review articles included infectious diseases, malignancy, gastric problems, and others. Others included chronic diseases and addiction related problems (Figure 3).

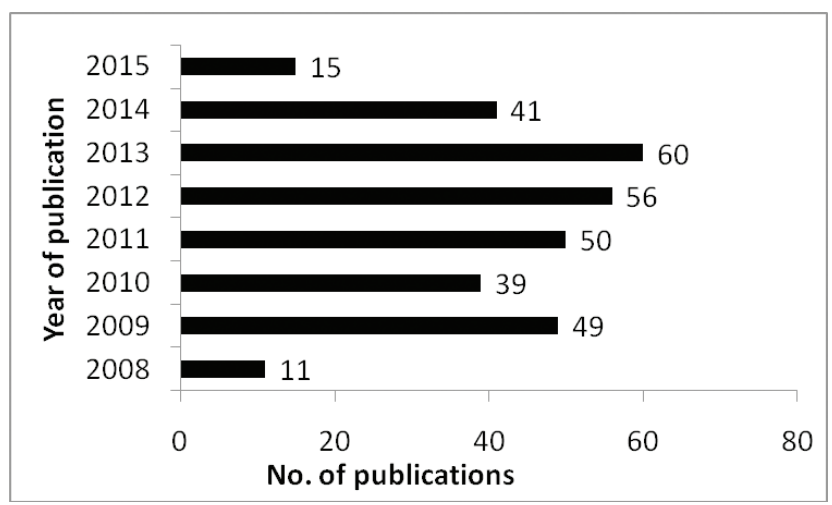

Figure 1: Year-wise distribution of total publications $(\mathrm{N}=321)$

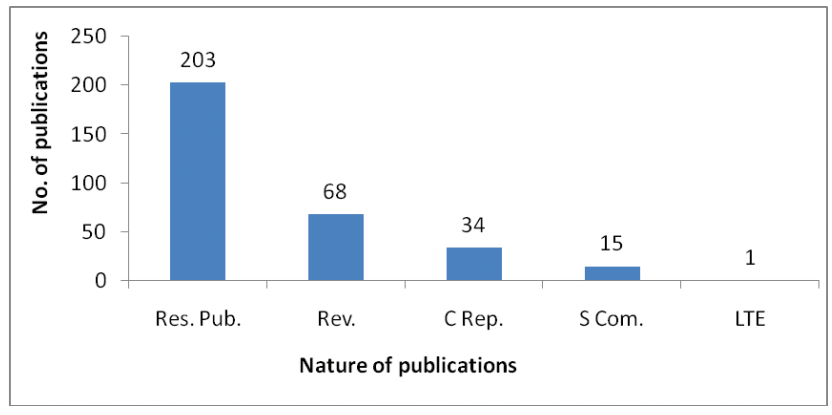

Figure 2: Categories of publications $(\mathrm{N}=321)$

Res. Pub.-Research publication, Rev.- Review, C Rep.- Case report, 5 Com.-Short communication, LTE-Letter to editor.

Research articles, case reports, and other studies have covered different therapeutic regions like infectious diseases, metabolic disorders, CVS disorders, psychiatric problems, pulmonological disorders, and skin disorders. (Figure 4) Category of others included pain, addiction, poisoning and chronic diseases. Metabolic disorders included T2DM, thyroid disorders, and obesity. Infectious diseases covered HIV/AIDS, TB, malaria, surgical infections, and other infections. 70 publications out of 244 were on general topics (Figure 4).

Published studies were conducted in different areas including adherence to treatment, effect of a treatment, adverse drug reactions reporting, drug utilization reviews, prevalence studies, drug related problems, quality of life of patients and surveys. 57 publications 


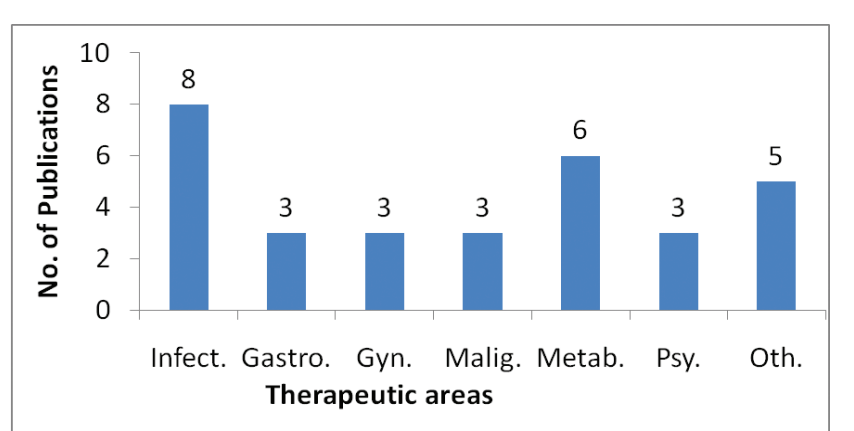

Figure 3: Review articles vis-à-vis therapeutic areas $(\mathrm{N}=31)$ Infect.-Infectious diseases; Gastro- Gastroenterological disorders; Gyn.Gynecology; Malig.- Malignancy; Metab.- Metabolic disorders; Psy.- Psychiatric problems; Oth-Others.

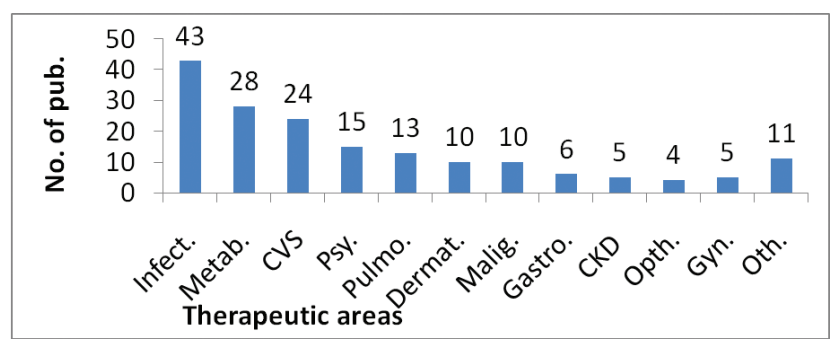

Figure 4: Non-review articles vis-à-vis therapeutic areas ( $N=174)$

Infect.-Infectious diseases; Gastro- Gastroenterological disorders; Gyn. Gynecology; Malig.- Malignancy; Metab.- Metabolic disorders; Psy.- Psychiatric problems; Oth-Others; CVS- Cardiovascular disease; Pulmo- Pulmonary disorders; Dermat.- Dermatological problems; CKD- Chronic kidney disease; OpthOphthalmology.

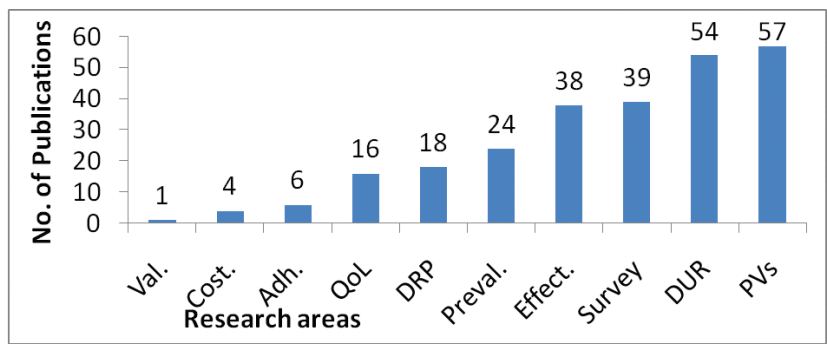

Figure 5: Profile of research areas of publications $(\mathrm{N}=244)$ Val.- Validity; Cost.- Costing; Adh.- Adherence; QoL- Quality of life; Preval.Prevalence; Effect.- Treatment effect; DUR- Drug Utilization Research; PVPharmacovigilance.

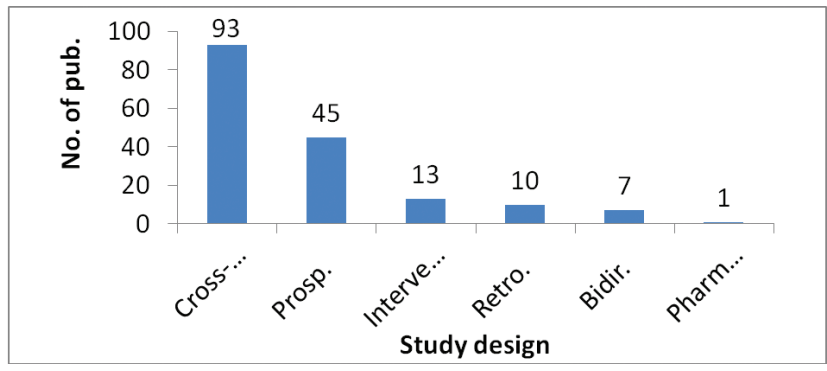

Figure 6: Reported Study designs of various studies ( $\mathrm{N}=169)$ Cross-sect- Cross-sectional; Prosp.- Prospective; Intervent.- Interventional; Retro.Retrospective; Bidir.- Bidirectional; Pharmaco.- Pharmacoeconomics.

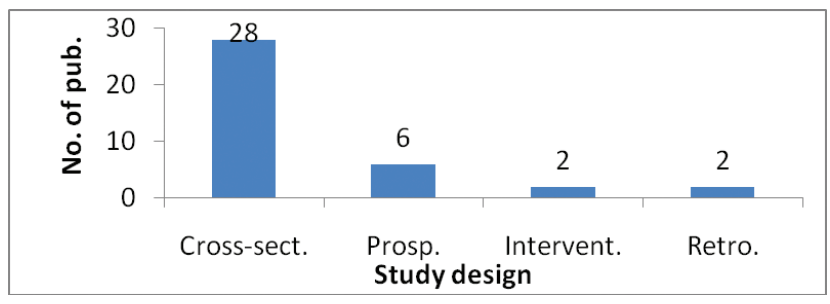

Figure 7: Profiling of not reported study designs $(\mathrm{N}=38)$ Cross-sect-Cross-sectional; Prosp.- Prospective; Intervent.- Interventional; Retro.Retrospective; Bidir.- Bidirectional; Pharmaco.- Pharmacoeconomics.

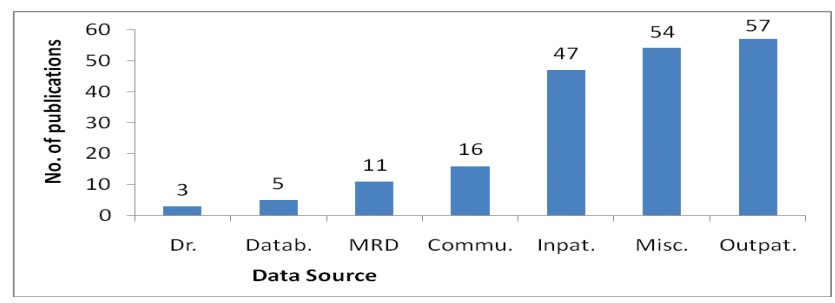

Figure 8: Data sources in Research studies ( $\mathrm{N}=193)$

Dr.- Doctor; Datab- Database; MRD- Medical Record Department; CommuCommunity; Inpat.- Inpatients; Misc.- Miscellaneous; Outpat.- Outpatients.

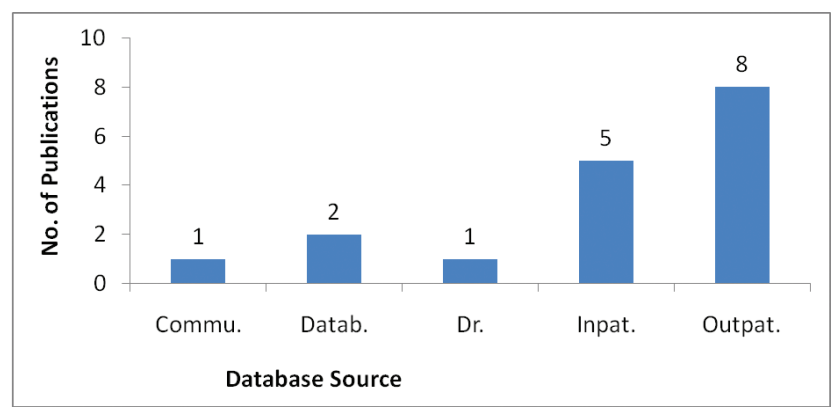

Figure 9: Profiling of data sources in not reported case $(\mathrm{N}=17)$ Dr.- Doctor; Datab- Database; MRD- Medical Record Department; CommuCommunity; Inpat.- Inpatients; Misc.- Miscellaneous; Outpat.- Outpatients.

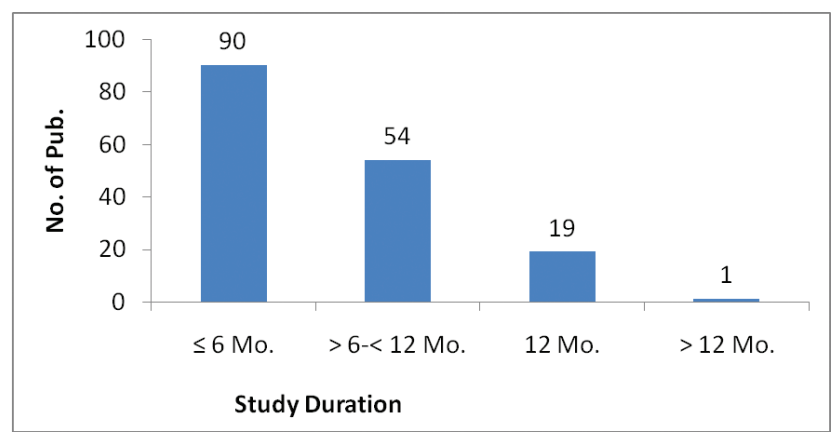

Figure 10: Research articles vis-à-vis study duration ( $N=164)$

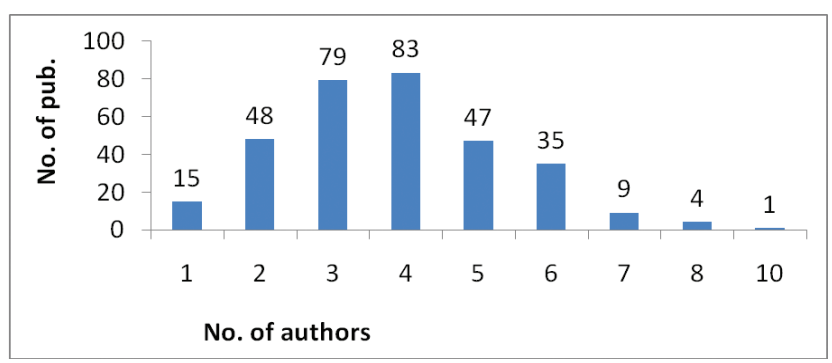

Figure 11: Publications vis-à-vis number of co-authors $(\mathrm{N}=321)$

Indian Journal of Pharmacy Practice, Vol 9, Issue 2, Apr-Jun, 2016 


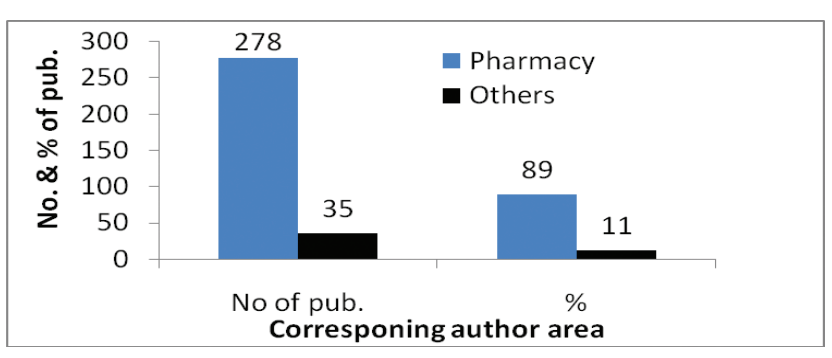

Figure 12: Publications vis-à-vis area of corresponding authors $(\mathrm{N}=313)$

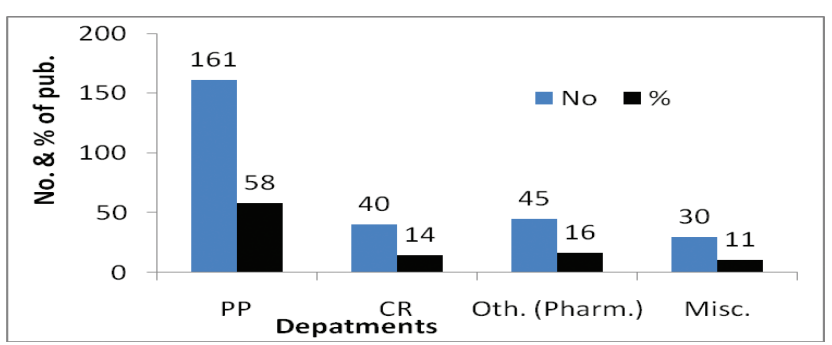

Figure 13: Profile of corresponding authors' area of working $(\mathrm{N}=276)$

PP-Pharmacy Practice; CR-Clinical Research; Oth-Other department of Pharmacy; Misc- Miscellaneous.

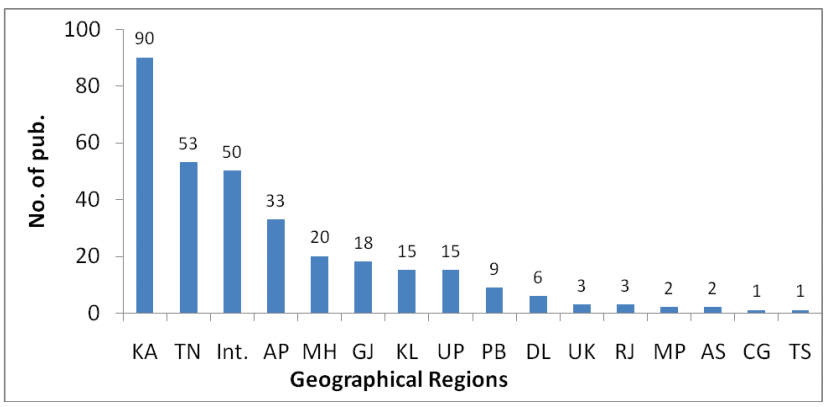

Figure 14: Profiling of publications region-wise $(\mathrm{N}=321)$

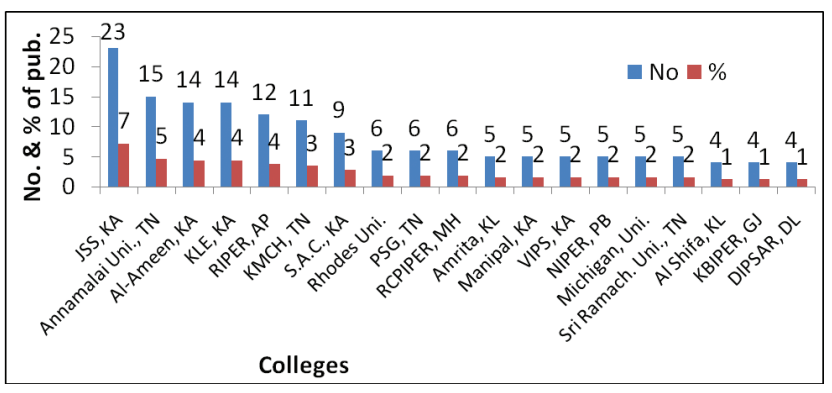

Figure 15: College-wise distribution of publications $(\mathrm{N}=321)$

focussed on ADRs and 51 on drug utilization studies. 39 surveys were performed and 16 studies evaluated the quality of life (Figure 5).

203 were research articles out 321 published work and 15 were short communications. Study design of 163 research articles and 6 short communication studies were reported. 93 studies out of 169 were crosssectional in nature followed by 45 prospective studies
(Figure 6). 41(out of 210 research publications; 203 research articles and 7 short communication) publications did not contain any information on study design. These were individually read by the co-authors and a consensus on design was arrived at. 28 were cross-sectional and 6 studies included prospective study design. Three were ambiguous; hence, not included in the analysis (Figure 7).

Out of 210 research articles, 193 studies mentioned their source of data collection. Data sources were prescriptions of outpatients \& inpatients, databases, medical record department, community and physicians (Figure 8). Data source was not reported in 17studies (Figure 9).

The studies were evaluated on the basis of duration. Study duration was mentioned in 164 publications out of 210 research publications. Study duration was less than 6 months in 90 studies and 54 studies had duration in the range of 6-12 months (Figure 10).

Publications were evaluated in respect of number of authors. Only one study had 10 authors, which was highest number came across. Highest number of publications (83) were with 4 authors followed by 79 studies were with 3 authors (Figure 11).

Working area of corresponding authors was evaluated for 321 publications. We could find information for corresponding author from 313 publications. Out of 313 studies, 278 studies had corresponding authors from pharmacy background. Corresponding authors in rest of 35 studies were from medicine, industry and other professional backgrounds (Figure 12).

Out of 321 publications, 276 studies contained the information on departments of publication. Out of 276, 161 studies were from pharmacy practice department followed by 45 studies by other departments of pharmacy area included pharmacology, pharmacognosy, pharmaceutical chemistry and pharmaceutical sciences. 40 studies out of 276 were from clinical research department (Figure 13).

Out of 321 studies, 90 studies were from Karnataka followed by 53 studies from Tamil Nadu. 50 studies were from international regions (Figure 14).

JSS College of pharmacy published 23 articles out of 321 followed by 15 publications of Annamalai University. $\mathrm{Al}$-ameen college of pharmacy and KLE College of pharmacy published 14 articles individually (Figure 15).

Study site in 171 studies was hospital out of 321 studies followed by 18 studies which were conducted at pharmacy setting and 16 studies were conducted in community. Study site was not reported in 7 studies (Figure 16). Amongst study sites, 146 were tertiary care hospitals, 16 secondary and 9 were primary care hospital. 47 studies 


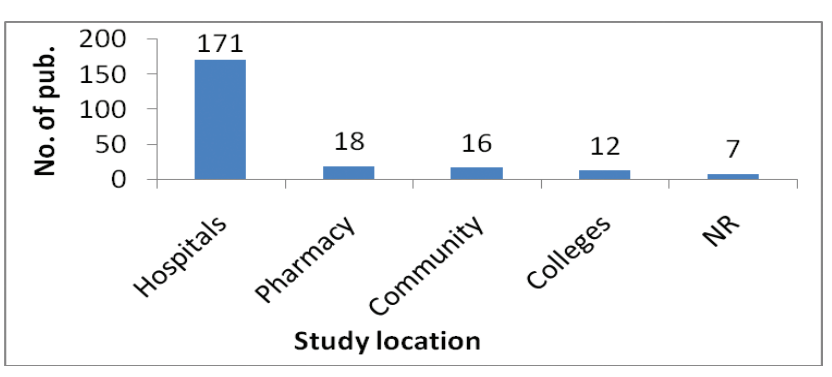

Figure 16: Profiling of Study site $(\mathrm{N}=210)$

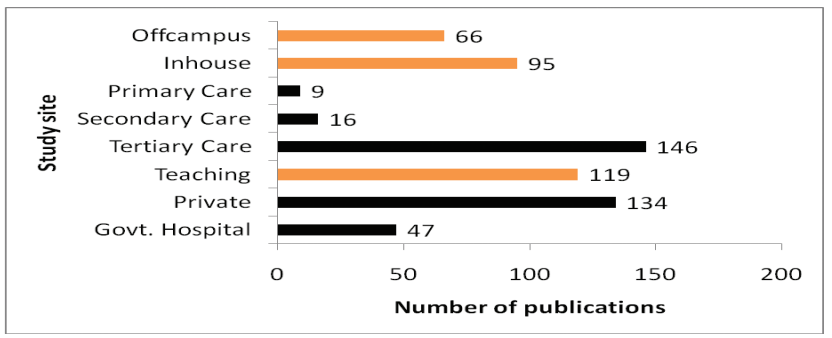

Figure 17: Profiling of study sites $(\mathrm{N}=210)$

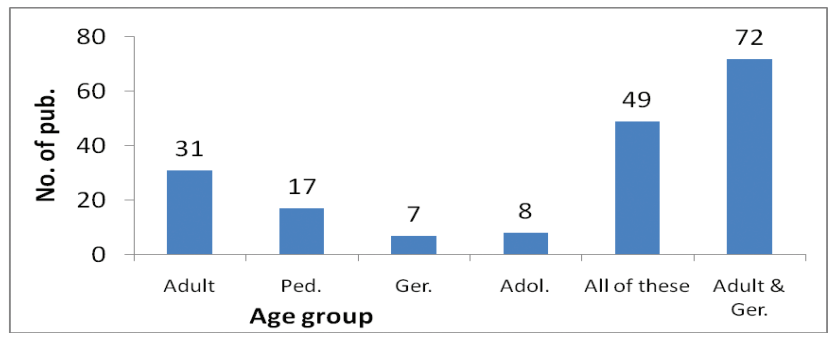

Figure 18: Profiling of sample population on the basis of age group $(\mathrm{N}=184)$

were conducted at Govt. hospital and 134 at private hospitals. Studies in 66 publications were carried out in collaboration of off campus hospitals (Figure 17).

Various age groups were studied in research articles. Sample population was adult in 31 studies and geriatric in seven studies (Figure 18).

\section{DISCUSSION}

This discussion is based on the analysis of studies published in IJOPP since 2008. Published work is categorized into research articles, reviews, short communication, case report, and letter to editor.

The total number of studies published in all issues of journal was found to be increased from 2008 to 2013, than it was decreased in 2014 (11 to 60; 41). When we had a look on the published studies in each issue of the journal, the number of studies was found equal in issues of Jan-Mar and Jul-Sept, while lesser in April-June. The number of studies published was found maximum in issues of Oct-Dec.
Research articles were found to be published more commonly then review and others, as most of the studies were based on the students' project work. Only 34 case reports were published in all the volumes published till date. Most of the authors in the present study are from pharmacy background this could be the possible reason for less number of case reports. ${ }^{17}$

Research in the field of ADR and DUR doesn't require long term follow up and can be carried out in short span of time. So publications with short duration and higher number in area of pharmacovigilance were found. From findings, we can observe that there is lack of data on validation, costing and medication adherence.

Less number of studies in retrospective categories (10 studies) could be justified as less practice of using database in hospitals and lack of databases availability in India. Study duration was not reported in 46 studies (out of total 210 published studies). As most of the study carried out in less than six month of duration, so cross-sectional study design was the most commonly observed design.

Out-patients and In-patients data sources were most commonly utilized for research purpose as most of the research studies were carried out in Hospitals. ${ }^{18}$ Information on the source for data collection was not reported in 17 original research publications of 210 .

Information was not available regarding corresponding authors' affiliation for 8 studies (out of total 321). There was no information of authors department in 45 studies (45/321). It was found that only 15 studies were on the name of single author; this might be due to high number of research studies which required a team work.

Karnataka and Tamil Naidu were found at the top in chart, $90 \& 53$ studies, retrospectively. This could be justified by the findings which shows the higher number of studies from pharmacy practice department and most of the colleges offering M Pharm in pharmacy practice and Pharm D belongs to these states. ${ }^{7,8}$

Hospitals were the most common study site. Most of the research was from the pharmacy practice department which works in collaboration with the hospitals for their project work. Study site was not mentioned in seven studies under the category of original research and short communication.

On comparison of collaborative and in-house study site setting, publications were found higher with in-house setting. It shows that facility of in-house study site setting increases the feasibility of research work.

Most of the studies were published by JSS college of Pharmacy, this could be explained by the fact that this is one of the first colleges in India where the course of pharmacy practice was started. ${ }^{6}$

Indian Journal of Pharmacy Practice, Vol 9, Issue 2, Apr-Jun, 2016 
Adult and geriatric population was the most studied population as this group counts for majority of population. The number of reporting from pediatric and geriatric groups need to be improved.

In first published issue of 2009, title of one research article did not match to its content and it was found the repetition of title of one research article of $2008 .^{19,20}$

In third issue of 2009, one study under the category of research article was a pharmacoeconomical research in actual, so there could be a separate category in journal for such type of researches.

In abstract of a published research article at online portal of first issue of 2011, content did not match to its title. But its title and content was matching in full text of the article. ${ }^{21}$ In research article of third issue of 2011, content of abstract did not match to the full study. ${ }^{22}$ In abstract of a published research article at online portal of first issue of 2012 content did not match to its title. But its title and content was matching in full text of the article. ${ }^{23}$ In second issue of 2012 repetition of one article of 2011 was found. ${ }^{24}$ However two studies pertaining to quality of life published in research category first and second issue of 2012, respectively but they should be placed in category of reviews. ${ }^{25,26}$ One study published in third issue of 2014 should have been included in category of case report. ${ }^{27}$

Strengthening The Reporting of Observational Studies in Epidemiology (STROBE) guideline was used for the reporting of observational studies. ${ }^{28}$ STROBE guideline did not address several issues for the health data collected without any defined research goals. For such studies, Reporting of studies Conducted using Observational Routinely-collected health Data (RECORD) Statement was used. ${ }^{29}$ These guidelines provide the minimum reporting standards for research articles to assess and use the study findings. Without these crucial information findings cannot be trusted. These guidelines help us in interpreting the procedural discrepancies related to carry out of study or in analysis of findings, so that the findings are reproducible. Accurate reporting helps in promoting the usability of the published research while incomplete, misleading or underreporting seriously impact the research usability and value.

In 38 out of total 210 publications under the category of original research articles and short communications, study design was not mentioned even in the full text.

In 47 research articles, study design was prospective but according to STROBE guidelines, the design should be cross-sectional in nature.

In one research article of first issue of 2012, study design as prospective-retrospective was mentioned but fact is that data collection was done in this way, study design is cross-sectional in actual. ${ }^{30}$

In one publication of fourth issue of 2010, study design was cross-sectional but it should be prospective in nature since they had two arms and compared it. ${ }^{31}$

Study design in 15 publications was retrospective but 13 publications should be cross-sectional and 2 studies should be prospective in nature. Study design in 13 surveys was not mentioned and surveys are crosssectional in nature.

\section{CONCLUSION}

Infectious diseases were found to be the most studied therapeutic area (51/321). Amongst the research areas; pharmacovigilance studies top the chart with 57 studies. Studies design was not reported in 38 studies. Most of the studies were carried for less than 6 months. Most of the published articles were from south India. Tertiary care hospitals were most common site. Adults and geriatric age group were found to be most commonly studied.

\section{ACKNOWLEGEMENT}

The authors are thankful to the editorial office of the IJOPP for their meticulous help in providing soft copies of the papers not available otherwise.

\section{CONFLICT OF INTEREST}

The author declare no conflict of interest.

\section{REFERENCES}

1. Basak SC, Sathyanarayana D. Pharmacy education in India. Am J Pharm Educ. 2010;74(4):68.

2. Mohanta GP, Manna PK, Valliappan K, Manavalan R. Achieving good pharmacy practice in community pharmacies in India. Am J Health Syst Pharm. 2001;58(9):809-10.

3. Mangasuli S, Rajan S, Khan SA. A decade of pharmacy practice education in India: Am J Pharm Educ. 2008;72(1):16.

4. Deshpande PR, Vantipalli R, Chaitanya Lakshmi CH, Rao EJ, Regmi B, et al. Clinical pharmacists: The major support to Indian healthcare system in near future. J Pharm Bioallied Sci. 2015;7(3):161-74.

5. Parthasarathi G, Ramesh M, Nyfort-Hansen K, Nagavi BG. Clinical pharmacy in a South Indian teaching hospital. Ann Pharmacother. 2002;36(5):927-32.

6. Department of pharmacy practice. JSS University JSS College of Pharmacy, Ooty. [cited 20157 Dec]; Available from: http://www.jsscpooty.org/departmentpharmacy-practice- 0 .

7. List of college offering M Pharm in pharmacy practice. [cited 2015 Dec 7]; Available from: https://targetstudy.com/colleges/mpharm-pharmacy-practicedegree-colleges-in-india.html.

8. Institutes offering both Pharm.D. and Pharm.D. (Post Baccalaureate) courses. Pharmacy council of India. [cited 2015 Dec 7]; Available from: http://www.pci. nic.in/CollegesCourses/Baccalaureate.aspx.

9. Indian journal of pharmacy practice: an official publication of Association of Pharmaceutical Teachers of India (APTI). [cited 2015 Dec 7]; Available from: http://www.ijopp.org/content/about-journal. 
10. Medical therapeutic area descriptions. centerwatch. [cited 2015 Dec 7]; Available from: https://www.centerwatch.com/clinical-trials/listings/therapeuticdescription.aspx.

11. What Are the Different Types of Clinical Research?. U.S. Food and Drug Administration. [cited 2015 Dec 7]; Available from: http://www.fda.gov/ ForPatients/ClinicalTrials/Types/default.htm.

12. Larsen MD, Cars T, Hallas J. A MiniReview of the use of hospital-based databases in observational inpatient studies of drugs. Basic Clin Pharmacol Toxicol. 2013;112(1):13-8.

13. Carlson MDA, Morrison RS. Study Design, Precision, and Validity in Observational Studies. Journal of Palliative Medicine. 2009;12(1):77-82.

14. Mann CJ. Observational research methods. Research design II: cohort, cross sectional, and case-control studies. Emerg Med J. 2003;20(1):54-60.

15. Types of study. Introduction to evidence based practice. [cited 2015 Dec 7] Available from: http://guides.mclibrary.duke.edu/c.php?g=158201\&p=1036068.

16. Primary, secondary and tertiary healthcare. Indian economic service. [cited 2015 Dec 7]; Available from: http://www.arthapedia.in/index.php?title=Primary, Secondary_and_Tertiary_HealthCare.

17. Gaurav G, Pramil T, Rajiv A. A Case of Nimesulide toxicity in an Indian Child. Indian Journal of Pharmacy Practice. 2012;5(2):57-8.

18. Pramil T, Rajiv A, Gaurav G. Prescription practice in patients of upper respiratory tract infection at a pediatric outpatient clinic in Punjab. Indian Journal of Pharmacy Practice. 2014;7(2).

19. Mallayasamy SR, Fayazkhan M, Kishore G, Acharya LD, Rao PG. Evaluation of drug information service provided by clinical pharmacy department based on provider and enquirers' perspective. Indian Journal of Pharmacy Practice. 2008;1(1).

20. Kuchake V, Maheshwari O, Surana S, Patil P, Dighore P. Evaluation of Drug Information Service provided by Clinical Pharmacy Department based on Provider and Enquirers' Perspective. Indian Journal of Pharmacy Practice. $2009 ; 2(1)$.
21. Vijayapandi P. Prescription errors in Guntur district of Andhra PradeshA retrospective study. Indian Journal of Pharmacy Practice. 2011;4(1).

22. Raghu K, Srinivasa R, Mohanta G, Manna P, Manavalan R. Role of Telmisartan in Controlling Morning Blood Pressure Surge. Indian Jornal of Pharmacy Practice. 2011;4(3).

23. Elizabeth S, Kia R, Yagnik R, Nagaraju K. Knowledge, Attitude and Skills of Nurses of Delhi towards Adverse Drug Reaction Reporting. Indian Journal of Pharmacy Practice. 2012;5(1).

24. Patel I, Chang J, Srivastava J, Balkrishnan R. India's Progress towards the health related Millennium Development Goals-Child Mortality. Indian Jornal of Pharmacy Practice. 2011;4(4)

25. Garg V. Comparison of the Quality of Life of Type 2 Diabetes Mellitus Patients Treated with Biguanides, Thiazolidinediones and Sulphonyl ureas. Indian Journal of Pharmacy Practice. 2012;5(1).

26. Radhika N, Anoop P, Praveen Kumar NVRT, Sarvana KRT, Madhusudhan S, Mohanta GP, et al. Measurement of Quality of Lifein Heart Failure-assessment over two Decades. Indian Journal of Pharmacy Practice. 2012;5(2).

27. Prasad T, Kalaiselvan V, Surabhi S, Vivek D, Ranvirkumar S, Nath G. Atorvastatin Induced Vasculitis. Indian Journal of Pharmacy Practice. 2014;7(3).

28. Vandenbroucke JP, von Elm E, Altman DG, Gotzsche PC, Mulrow CD, Pocock SJ, et al. Strengthening the Reporting of Observational Studies in Epidemiology (STROBE): explanation and elaboration. Int J Surg. 2014;12(12):1500-24.

29. Benchimol El, Smeeth L, Guttmann A, Harron K, Moher D, Petersen I, et al. The REporting of studies Conducted using Observational Routinely-collected health Data (RECORD) Statement. PLoS Med. 2015;12(10).

30. Elizabeth S, Kia R, Yagnik R, Nagaraju K. Prescribing Pattern of Antiepileptic Drugs in Adults in a South Indian Tertiary care Hospital. Indian Journal of Pharmacy Practice. 2012;5(1).

31. Murugesan SMN. Treatment of Obesity with Sibutramine, Metformin, Acarbose and Lifestyle Modifications: A Cross-Sectional Study. Indian Journal of Pharmacy Practice. 2010;3(4):45-50. 